\title{
Surveillance of spinal cord injuries in Utah, USA
}

\author{
D J Thurman MD MPH, ${ }^{1} \mathrm{C}$ L Burnett $\mathrm{BS},{ }^{2} \mathrm{~L}$ Jeppson $\mathrm{MS},{ }^{3} \mathrm{D}$ E Beaudoin MD \\ MSPH, ${ }^{4} \mathrm{~J}$ E Sniezek MD MPH ${ }^{1}$ \\ ${ }^{1}$ Medical Epidemiologist, National Center for Injury Prevention and Control, Centers for \\ Disease Control and Prevention, 4770 Buford Highway, NE, Mailstop F41, Atlanta, \\ Georgia 30341, USA; ${ }^{2}$ Research Analyst, ${ }^{3}$ Research Statistician, ${ }^{4}$ Medical Epidemiologist, \\ Division of Community Health Services, Utah Department of Health, PO Box 16660, Salt \\ Lake City, Utah 84116-0650, USA
}

From 1989 through 1991, we conducted surveillance of spinal cord injury (SCI) among residents of Utah. We found an annual incidence rate of 4.3 per 100,000 , with the highest rates occurring among males 15-24 years of age. Motor vehicles were the leading cause of injury, followed by falls, and sports and recreation. We also examined the accuracy and completeness of reporting in this surveillance system. We found the predictive value positive of SCI diagnoses reported in hospital discharge data to be only $61 \%$. When we considered only patients who received acute hospital care in-state, we found that the sensitivity of hospital discharge data was $89 \%$. These findings indicate serious problems in the reporting of spinal cord injury diagnoses in hospital discharge data and the need to verify case reports based on these data. There is also a need to study this problem in other jurisdictions to determine if overreporting is widespread.

Keywords: spinal cord injuries; epidemiology; incidence; sensitivity; predictive value.

\section{Introduction}

Published epidemiologic studies of spinal cord injury in the United States have estimated the annual incidence rate at between 4.0 and 5.3 per 100,000 population. ${ }^{1-4}$ These estimates, however, may not reflect the current US incidence of spinal cord injury, because a number of these studies were conducted in limited geographic areas and most were based on data collected before 1980. To improve measures of the current incidence of these injuries and to develop more effective methods of prevention, the US Centers for Disease Control and Prevention (CDC) and the Council of State and Territorial Epidemiologists (CSTE) have supported the development of state and local spinal cord injury surveillance systems. ${ }^{5,6}$ Since 1987 , a number of state health departments have designated SCI a reportable health condition and have developed surveillance systems to monitor these injuries. 5

Many of these surveillance systems iden- tify cases of SCI through hospital discharge data, which code diagnostic information according to the International Classification of Disease, Ninth Revision, Clinical Modification (ICD-9-CM). ${ }^{7}$ These systems depend on the accuracy and completeness of this coding.

The purpose of this paper is to report the current incidence of SCI in a state population and to describe the accuracy (predictive value positive) and completeness (sensitivity) of hospital discharge data as a source for information on spinal cord injury in a state surveillance system.

\section{Material and methods}

We examined morbidity and mortality from SCI among all Utah residents from January 1, 1989 through December 31, 1991. In accordance with the definition proposed by CDC and CSTE, ${ }^{6}$ we defined SCI as an acute, traumatic lesion of neural elements in the spinal canal (including spinal cord and 
cauda equina) resulting in any degree of sensory deficit, motor deficit, or neuropathic deficit of bowel or bladder function, either transient or persistent. Only persons who were hospitalised or who died were included; persons with lesions due to degenerative disc disease were excluded. Hospitals used ICD-9-CM coding ranges $806.00-806.9$ and $952.00-952.9^{7}$ to identify persons with SCI from discharge data.

SCI is a reportable health condition in Utah. Cases were ascertained through the statewide reporting system of the Utah Department of Health, Bureau of Epidemiology. This system identifies cases from three sources: (1) discharge data from all the state's acute care hospitals, (2) lists of patients with spinal cord injury from all the state's inpatient rehabilitation units, and (3) state death certificates. The health department obtained discharge data separately from each hospital or hospital system, not from a uniform statewide hospital discharge dataset. Reports from all sources contained personal identifiers, which allowed researchers to match and merge duplicate records.

Health department personnel reviewed and abstracted each patient's medical records to verify the diagnosis and to obtain information on patient demographics and cause, nature, and severity of injury. The record reviewers were trained and closely supervised by a physician, who reviewed the abstracted data for each case.

The sensitivity of hospital discharge data was defined as the proportion of persons who had received acute care for SCI in a Utah hospital who were identified through discharge data. Predictive value positive (PVP) was defined as the proportion of persons identified by hospital discharge data as having acute SCI whose diagnoses were verified. Both sensitivity and predictive value positive were calculated using standard formulae for surveillance systems. ${ }^{8}$

\section{Results}

From 1989 to 1991, 223 cases of SCI were verified, for a crude incidence rate of 4.3 per 100,000 population per year (4.7 per 100,000 , age-adjusted to the 1980 US popu- lation). The largest number of injuries occurred among males (76\%) and among persons aged $15-24$ years $(30 \%)$ (Fig 1). The median age at time of injury was 29 years.

Motor vehicle crashes were the leading cause of spinal cord injuries $(49 \%)$, followed by falls, sports and recreation, firearms, and diving (Table I). Twenty-two percent of cases had evidence of recent alcohol use.

Tetraparesis or tetraplegia resulted from $128(57 \%)$ of these injuries; paraparesis or paraplegia, from the remaining 95 (43\%). The severity of injury at the time of discharge from acute hospital care was assessed for each surviving patient according to guidelines of the American Spinal Injury Association. ${ }^{9}$ Forty-one cases $(18 \%)$ were

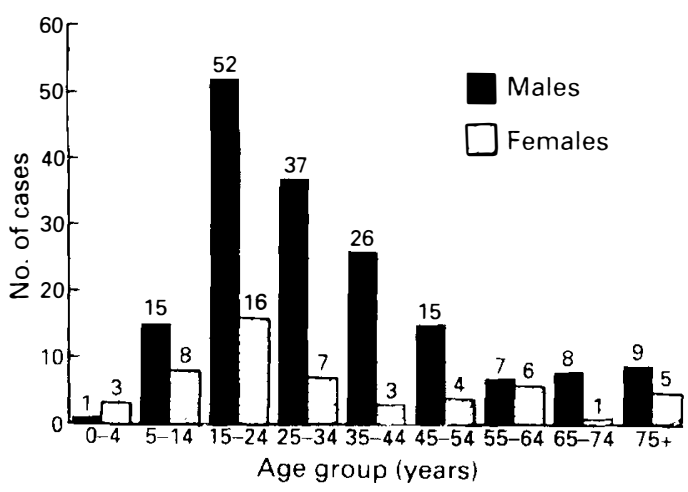

Figure 1 Spinal cord injuries by age and sex of persons.

Table I Distribution of spinal cord injury by cause

\begin{tabular}{lrc}
\hline Category & No. cases & Percent \\
\hline Motor vehicle & 110 & 49.3 \\
Falls & 47 & 21.1 \\
Sports and recreation & 24 & 10.8 \\
$\quad$ (excluding diving) & & \\
Firearms & 12 & 5.4 \\
Diving & 11 & 4.9 \\
Other & 18 & 8.1 \\
Unknown & 1 & 0.4 \\
All causes & 223 & 100.0 \\
\hline
\end{tabular}


fatal; 21 persons died before being admitted to a hospital. One hundred and ten persons $(49 \%)$ had severe impairment of neurological function below the injured spinal cord segment (Frankel class A, B, or C). Function in the affected segments was substantially preserved (Frankel class D) for $46(21 \%)$ and $25(11 \%)$ returned to full neurological function. Severity of one case could not be assessed.

Hospitals originally reported 289 cases. Of these only 175 cases were accurately coded and met the case definition, for an accuracy rate or predictive value positive of only $61 \%$ for the 3 years (Table II).
The coding accuracy of hospital discharge data during two of the three study years (1990-1991) was examined separately for each ICD-9-CM rubric (Table III). These data indicate that miscoding is frequent under both rubrics, but more common under 952. False-positive reporting occurred in all hospitals reporting more than one SCI.

The reasons for miscoding were examined. Of 114 records miscoded during the three study years, $75 \%$ were for patients admitted following trauma but without evidence of neurological deficits (Table IV). Fifteen percent were for patients hospitalised for nontraumatic spinal cord disease.

Table II Proportion of reported spinal cord injuries that were verified, by year

\begin{tabular}{lccc}
\hline Year & $\begin{array}{c}\text { Verified } \\
\text { No. }(\%)\end{array}$ & $\begin{array}{c}\text { Not verified } \\
\text { No. }(\%)\end{array}$ & $\begin{array}{c}\text { Total } \\
\text { no. }\end{array}$ \\
\hline 1989 & $57(54)$ & $48(46)$ & 105 \\
1990 & $59(63)$ & $35(37)$ & 94 \\
1991 & $59(66)$ & $31(34)$ & 90 \\
Total 1989-1991 & $175(61)$ & $114(39)$ & 289 \\
\hline
\end{tabular}

Table III Proportion of reported spinal cord injuries that were verified, 1990-91, by ICD-9 category

\begin{tabular}{lccr}
\hline ICD-9-CM code & $\begin{array}{c}\text { Verified } \\
\text { No. }(\%)\end{array}$ & $\begin{array}{c}\text { Not verified } \\
\text { No. }(\%)\end{array}$ & $\begin{array}{c}\text { Total } \\
\text { no. }\end{array}$ \\
\hline $806.00-806.9^{\mathrm{a}}$ & $76(72)$ & $30(28)$ & 106 \\
$952.00-952.9^{\mathrm{b}}$ & $42(55)$ & $34(45)$ & 76 \\
Original report code lost & $0(0)$ & $2(100)$ & 2 \\
Total 806 and 952 & $118(64)$ & $66(36)$ & 184 \\
\hline
\end{tabular}

${ }^{a}$ Fracture of vertebral column with spinal cord injury.

${ }^{\mathrm{b}}$ Spinal cord injury without evidence of spinal bone injury.

Table IV Categories of miscoding in nonverified hospital reports of spinal cord injury, 1989-1991

\begin{tabular}{lcr}
\hline Reason not verified & No. reported & $(\%)$ \\
\hline No neurological deficits described & 85 & $(75)$ \\
Nontraumatic spinal cord disease & 17 & $(15)$ \\
Late effects of old spinal cord injury & 8 & $(7)$ \\
Other neurological injury (brain, nerve root) not & 4 & $(4)$ \\
$\quad$ involving spinal cord & & $(101)^{\mathrm{a}}$ \\
\hline
\end{tabular}

Exceeds 100 due to rounding error. 
In addition to the 175 verified cases of SCI reported by hospitals, 27 cases were ascertained from death certificates and 19 from separate reports from rehabilitation units (Table V). Hospital discharge data identified 174 of 196 patients who had received in-state acute hospital care, a sensitivity of $89 \%$. The proportion of all verified cases of SCI ascertained through hospital discharge data was $78 \%(175 / 223)$.

\section{Discussion}

The incidence rate of SCI found in Utah is similar to rates reported in studies published more than a decade ago. Based on Utah's age-adjusted incidence rate of 4.7 per 100,000 , an estimated 12,000 spinal cord injuries now occur in the United States each year. As found in other studies, males, adolescents, and young adults continue to be at highest risk for these injuries. Motor vehicle crashes remain the leading cause of SCI - the detailed analysis of spinal cord injuries due to motor vehicle crashes in Utah is the subject of a separate paper. ${ }^{10}$ The burden of mortality and severe morbidity from spinal cord injuries clearly indicates an urgent need for improved prevention strategies. Ongoing surveillance is essential to indicate areas of greatest need and to provide information necessary to evaluate prevention effectiveness.

This investigation indicates serious prob- lems in the accuracy of spinal cord injury reporting based on hospital discharge data. The large percentage of inaccurate coding indicates that additional verification measures may be needed in spinal cord injury surveillance systems based on hospital discharge data. These measures might include the review of medical records and comparisons of case reports with registries from hospital trauma and rehabilitation units that independently code or classify diagnoses.

The extent of this problem in other jurisdictions is unknown. As health department surveillance of SCI increases, this study should be replicated elsewhere to assess whether similar degrees of overreporting are widespread.

The evaluation of the sensitivity of reporting in hospital discharge data depends on the completeness with which SCI is ascertained from all sources. We believe the ascertainment of morbidity in this study was nearly complete, although persons injured outside the state who received neither acute treatment nor rehabilitation within the state would have been missed. The ascertainment of mortality was probably incomplete. Persons who died immediately from multiple severe injuries, especially head trauma, may have had undetected spinal cord injuries. ${ }^{11,12}$

This investigation indicates that the sensitivity of surveillance based only on hospital

Table V Verified cases of spinal cord injury by reporting source, 1989-1991

\begin{tabular}{llr}
\hline Category of hospital care & Source of case identification & No. \\
\hline Prehospital fatalities & Hospital discharge data & 1 \\
& Death certificate & 20 \\
Acute care in-state & All sources & 21 \\
& Hospital discharge data & 174 \\
& Rehabilitation registry & 13 \\
& Death certificate & 7 \\
Acute care out-of-state & Other & 2 \\
Total & All sources & 196 \\
& Rehabilitation registry & 6 \\
& All sources & 223
\end{tabular}

an-hospital fatalities reported through both hospital discharge data and death certificates are listed under hospital discharge data only. 
discharge data is about $90 \%$, but this excludes persons who die before reaching the hospital and those who are hospitalised out of state. More complete ascertainment of the incidence of SCI in a population requires surveillance systems that include reports from vital records or medical examiner records.

\section{Acknowledgements}

The authors express appreciation to Edma Diller, Craig R Nichols, Gerrie Thompson, and Gayle Wood for their assistance in this project. This study was funded by a grant from the US Centers for Disease Control and Prevention, National Center for Injury Prevention and Control.

\section{References}

1 Kraus JF, Franti CE, Riggins RS et al (1975) Incidence of traumatic spinal cord lesions. J Chron Dis 7 : 471-492.

2 Black WA, Jr, Albin M, Aronica MJ et al (1978) A comprehensive plan for spinal cord injury services in Pennsylvania. Penn Med 81: 29-54.

3 Kalsbeek WD, McLaurin RL, Harris BSH, Miller JD (1982) The national head and spinal cord injury survey: major findings. J Neurosurg 53: S19-S43.

4 Bracken MB, Freeman DH, Hellenbrand K (1981) Incidence of acute traumatic hospitalized spinal cord injury in the United States, 1970-1977. Am J Epidemiol 113: 615-622.

5 Centers for Disease Control (1988) Acute traumatic spinal cord injury surveillance-United States, 1987. MMWR CDC Surveill Summ 37: 285-286.

6 National Committee for Injury Prevention and Control (1989) Injury Prevention: Meeting the Challenge. Oxford University Press, New York: 290.

7 Health Care Financing Administration (1989) International Classification of Diseases, 9th Revision, Clinical Modification, 3rd edn. US Department of Health and Human Services, Washington DC.

8 Centers for Disease Control (1988) Guidelines for evaluating surveillance systems. MMWR CDC Surveill Summ 37: S-5: 1-18.

9 American Spinal Injury Association (1982) Standards for neurological and functional classification of spinal cord injury. American Spinal Injury Association, Chicago.

10 Thurman DJ, Burnett CL, Beaudoin DE et al (1993) Risk factors and mechanisms of occurrence in motor-vehicle-related spinal cord injuries: Utah. 37th Annual Proceedings. Association for the Advancement of Automotive Medicine, Des Plaines, Illinois: 201-208.

11 Alker GJ Jr, Oh YS, Leslie EV (1978) High cervical spine and craniocervical junction injuries in fatal traffic accidents: a radiological study. Orthop Clin North Am 9: 1003-1010.

12 Bucholz RW, Burkhead WZ, Graham W, Petty C (1979) Occult cervical spine injuries in fatal traffic accidents. J Trauma 19: 768-771. 